\title{
The Impact of Mechanical Ventilation Duration on the Readmission to Intensive Care Unit: A Population-Based Observational Study
}

\author{
Hyun Woo Lee, M.D. ${ }^{1}$ (i) and Young-Jae Cho, M.D., M.P.H., Ph.D. ${ }^{2}$ (iD \\ ${ }^{1}$ Division of Pulmonary and Critical Care Medicine, Department of Internal Medicine, Seoul Metropolitan Government- \\ Seoul National University Boramae Medical Center, Seoul, ${ }^{2}$ Division of Pulmonary and Critical Care Medicine, Department \\ of Internal Medicine, Seoul National University Bundang Hospital, Seoul National University College of Medicine, Seongnam, \\ Korea
}

Background: If the duration of mechanical ventilation (MV) is related with the intensive care unit (ICU) readmission must be clarified. The purpose of this study was to elucidate if prolonged MV duration increases ICU readmission rate. Methods: The present observational cohort study analyzed national healthcare claims data from 2006 to 2015 . Critically ill patients who received MV in the ICU were classified into five groups according to the MV duration: MV for $<7$ days, $7-13$ days, 14-20 days, $21-27$ days, and $\geq 28$ days. The rate and risk of the ICU readmission were estimated according to the MV duration using the unadjusted and adjusted analyses.

Results: We found that 12,929 patients had at least one episode of MV in the ICU. There was a significant linear relationship between the MV duration and the ICU readmission $\left(\mathrm{R}^{2}=0.85, \mathrm{p}=0.025\right)$. The total readmission rate was significantly higher as the MV duration is prolonged (MV for $<7$ days, 13.9\%; for 7-13 days, 16.7\%; for 14-20 days, $19.4 \%$; for $21-27$ days, $20.4 \%$; for $\geq 28$ days, $35.7 \%$; $p<0.001$ ). The analyses adjusted by covariables and weighted with the multinomial propensity scores showed similar results. In the adjusted regression analysis with a Cox proportional hazards model, the MV duration was significantly related to the ICU readmission (hazard ratio, 1.058 [95\% confidence interval, 1.047-1.069], $\mathrm{p}<0.001$ ).

Conclusion: The rate of readmission to the ICU was significantly higher in patients who received longer durations of the MV in the ICU. In the clinical setting, closer observation of patients discharged from the ICU after prolonged periods of MV is required.

Keywords: Critical Illness; Mechanical Ventilation; Intensive Care Units; Patient Readmission; Mortality

Address for correspondence: Young-Jae Cho, M.D., M.P.H., Ph.D.

Division of Pulmonary and Critical Care Medicine, Department of Internal Medicine, Seoul National University Bundang Hospital, Seoul National

University College of Medicine, 82 Gumi-ro 173 Beon-gil, Bundang-gu, Seongnam 13620, Korea

Phone: 82-31-787-7058, Fax: 82-31-787-4050, E-mail: lungdrcho@snubh.org

Received: Mar. 14, 2020, Revised: Apr. 28, 2020, Accepted: Aug. 20, 2020, Published online: Aug. 21, 2020

@(c) It is identical to the Creative Commons Attribution Non-Commercial License (http://creativecommons.org/licenses/by-nc/4.0/) 


\section{Introduction}

The prognosis of critically ill patients is poor when they are readmitted to the intensive care unit (ICU) after being discharged from the ICU. ICU readmission is related to longer hospital stays, higher hospital mortality rates, and higher medical costs ${ }^{1-4}$. It is possible that the readmission rate could be lowered if the risk factors for readmission were identified and addressed. Therefore, elaborate efforts have been made to determine the risk factors for readmission to the $\mathrm{ICU}^{2,3}$ and to identify the patients at a higher risk of readmission in advance ${ }^{5,6}$. Most of the risk factors for ICU readmission are associated with impaired consciousness, severity of disease, and impaired cardiopulmonary function at discharge ${ }^{4,5,7}$. However, an accurate predictive model for ICU readmission has not yet been developed because of the complicated medical conditions of ICU patients ${ }^{5,6,8}$. Therefore, modifiable factors related to ICU readmission need further investigation.

Several studies have reported a relationship between prolonged mechanical ventilation (PMV) and poor post-discharge clinical outcomes. A PMV of $\geq 21$ days has been reportedly associated with a greater post-discharge mortality rate ${ }^{9}$. Even if patients with PMV survive in the ICU, the weaning rate is only about $50 \%$ and the probability of discharge to home is only about $20 \%{ }^{10}$. Low quality of life has been reported in surviving patients after PMV ${ }^{11}$. Although, the patients who stay in the ICU for a longer period are more likely to be readmitted to the $\mathrm{ICU}^{5,7}$, limited data exists to clarify whether the duration of mechanical ventilation (MV) is independently related to ICU readmission. Considering that the duration of MV can be reduced through better practice of the clinicians ${ }^{12,13}$, the relationship between duration of MV and ICU readmission rate needs to be identified. The purpose of this study was to analyze whether there is a difference in ICU readmission rates according to the duration of MV.

\section{Materials and Methods}

\section{Study design, setting, and data sources}

We followed the STROBE (Strengthening the Reporting of Observational Studies in Epidemiology) guidelines for designing the present study ${ }^{14}$. This historic cohort study was conducted using the National Sample Cohort (NSC) database (version 2.0) developed by the National Health Insurance Sharing Service. The NSC database selected 1,025,340 patients who claimed hospital charges from 2002 to 2015 by systematic stratified random sampling with proportional allocation and includes socio-demographic, clinical, and procedural information ${ }^{15}$. We analyzed 997,173 patients who were followed up from 2006 to 2015 with the informative data on readmission to ICU and post-discharge mortality. An MV event was identified by specific KCD-7 (7th revision of Korean Standard Classification of Diseases) codes in the claim database, which were considered highly accurate and exclusive (Supplementary Table S1) ${ }^{16}$.

\section{Patients}

The eligibility criteria were as follows: (1) critically illness, (2) age $\geq 18$ years, and (3) at least one MV code claim in ICU, regardless of the duration of MV. To exclude patients who required MV without critical illnesses, we only included patients who stayed for 3 or more days or those who expired in the $\mathrm{ICU}^{16}$. The patients were classified into five categories based on the duration of MV: MV for $<7$ days, 7-13 days, 14-20 days, $21-27$ days, and $\geq 28$ days.

\section{Variables}

We evaluated the socio-demographic characteristics including age, sex, residence in urban or rural areas, decile of income, admission to tertiary referral hospital, comorbidities, and Charlson comorbidity index (CCI). Patients were divided into three groups based on CCI $(0-1,2-3$, and $\geq 4)$. To evaluate the clinical features, we analyzed main diagnosis at the initiation of $\mathrm{MV}$, number of days spent in the hospital and ICU, number of days of MV, bedside therapeutic exercise, and rehabilitative breathing therapy.

We assessed clinical outcomes including the result of ICU management, the number of ICU readmission, total deaths during follow-up, time to ICU readmission, the rate of ICU readmission, and the source of ICU readmission. ICU readmission was defined as the second episode of ICU readmission after the first episode of ICU admission in a patient who had more than two admissions to ICUs during 10 years of observation period. All the patients were observed for at least 1 year. Cases of intra- or inter-hospital transfer between ICUs were considered one episode of ICU admission. Time to readmission was classified into five categories: within 2 days, 3 days, 7 days, 28 days, and total. The source of ICU readmission was classified into the ICU readmission after hospital discharge and the ICU readmission from a general ward before hospital discharge. Multinomial propensity scores were estimated with variables including age, sex, area of residence, income, admission to tertiary referral hospital, comorbidities, CCI, and main diagnosis at the initiation of $\mathrm{MV}^{13}$.

\section{Statistical methods}

Descriptive analyses were conducted to present the characteristics of the patients. Categorical variables were described as percentages and continuous variables were described as mean and standard deviation. The linear association between categorical variables and MV duration was evaluated using 
the linear-by-linear test for categorical variables and Spearman's correlation analysis for continuous variables. Pearson's correlation coefficient was estimated to reveal the association between MV duration and ICU readmission rate. A Poisson regression analysis was performed to estimate the unadjusted and adjusted incidence rate of ICU readmission in each group. A Kaplan-Meier curve with a log-rank test was used to assess differences in cumulative rates of ICU readmission. A multinomial propensity score-weighted logistic regression analysis was conducted to adjust for the putative risk of bias due to different baseline characteristics ${ }^{17}$. After the proportional hazards assumption were tested, univariable and multivariable analyses with a Cox proportional hazards model were conducted to reveal the adjusted impact of MV duration on ICU readmission.

The risk of ICU readmission was evaluated based on the group with an MV $<7$ days. Multicollinearity was measured with a variance inflation factor, and a cut-off value of 4 was regarded as high. Statistical significance was considered when $\mathrm{p}<0.05$. All the analyses were conducted using $\mathrm{R}$ for Statistical Computing software, version 3.4.3 (R Core Team [2017], Vienna, Austria).

\section{Ethical statement}

The Institutional Review Board Committee of Bundang Seoul National University Hospital examined and approved the protocol of this study, and the need for informed consent was waived given that we only accessed electronic medical records (Institutional Review Board number:X-1906-544-902).

\section{Results}

Among the 997,173 patients in the NSC database, 49,414 (5.0\%) had at least one episode of ICU stay for $\geq 3$ days or died in ICU and 12,929 (1.3\%) had at least one episode of MV in 837 ICUs (Figure 1). The median MV duration was 3 days (interquartile range [IQR], 1-8 days). Based on MV duration, patients were classified into five groups: 8,915 (70.0\%) patients with MV for $<7$ days, 2,171 (16.8\%) patients with MV for 7-13 days, 868 (6.7\%) patients with MV for 14-20 days, 378 (2.9\%) patients with MV for 21-27 days, and 597 (4.6\%) patients with
MV for $\geq 28$ days.

\section{Socio-demographic characteristics of the study population}

In the 12,929 patients with MV, a larger proportion of male and high income patients was found as MV duration increased (Table 1). The patients with longer MV duration were more found at tertiary referral hospitals. There were significant correlations between MV duration and several comorbidities. The patients with longer MV duration had a higher CCI score and were more likely to have a respiratory disorder at the initiation of MV. Rehabilitative breathing therapy was only conducted in about $6 \%$ of the included subjects and was performed more often in patients with longer periods of MV.

\section{Comparison of clinical outcomes}

The patients with longer MV duration were less likely to be discharged to home (Table 2). More patients were died in hospital as MV duration was prolonged in the subpopulation with $\mathrm{MV} \geq 7$ days $(\mathrm{p}<0.001)$. Among the survived 6,967 patients, $2,056(29.5 \%)$ were eventually readmitted to ICU for 10 years. The median time to readmission was 48 days (IQR, 23-822 days). Total ICU readmission rate and ICU readmission rate within 28 days was higher in the groups with longer MV duration $(\mathrm{p}<0.001)$. We did not find a significant relationship between MV duration and readmission to ICU until 7 days after discharge to the ward. In both sources of ICU readmission (from a general ward before hospital discharge and after hospital discharge), longer MV duration was significantly related with a higher ICU readmission rate. In addition, mortality (including in- and out-of-hospital death) was found to have a significant positive correlation with MV duration ( $\mathrm{p}<0.001$ ).

In the analysis of patients who survived in ICU and were discharged to the ward, ICU readmission rates increased according to MV duration $\left(\mathrm{R}^{2}=0.85, \mathrm{p}=0.025\right)$ (Figure $2 \mathrm{~A}$ ). In particular, patients with MV for $\geq 28$ days showed a more than 3 -fold higher readmission rate than those with MV for $<7$ days and a 2-fold higher readmission rate than those with MV for 14-20 days. The mortality rate increased according to MV duration, and more than half of the patients with MV for $\geq 21$ days died during the observation period (Figure 2B).

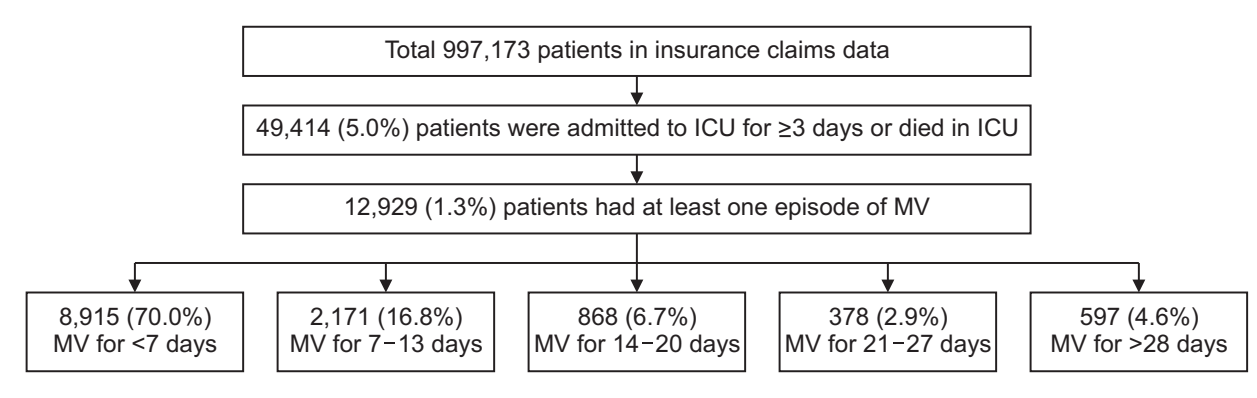

Figure 1. Flow chart of the patient inclusion according to the operational definition. ICU: intensive care unit; MV: mechanical ventilation. 
Table 1. Socio-demographic and clinical characteristics according to MV duration in the ICU

\begin{tabular}{|c|c|c|c|c|c|c|}
\hline & $\begin{array}{c}\text { MV for } \\
<7 \text { days } \\
(n=8,915)\end{array}$ & $\begin{array}{c}\text { MV for } \\
7-13 \text { days } \\
(n=2,171)\end{array}$ & $\begin{array}{c}\text { MV for } \\
\text { 14-20 days } \\
(n=868)\end{array}$ & $\begin{array}{c}\text { MV for } \\
\text { 21-27 days } \\
(n=378)\end{array}$ & $\begin{array}{c}\text { MV for } \\
\geq 28 \text { days } \\
(n=597)\end{array}$ & $\begin{array}{l}p \text {-value } \\
\text { for trend }\end{array}$ \\
\hline Age, yr & $65.19 \pm 14.96$ & $64.91 \pm 15.30$ & $65.19 \pm 15.28$ & $66.67 \pm 14.63$ & $66.16 \pm 15.56$ & 0.102 \\
\hline Male sex & $5,259(59.0)$ & $1,344(61.9)$ & $531(61.2)$ & $241(63.8)$ & $376(63.1)$ & 0.002 \\
\hline Residence in rural areas & $3,903(42.7)$ & $932(42.9)$ & $375(43.2)$ & $161(42.6)$ & $252(42.2)$ & 0.993 \\
\hline \multicolumn{7}{|l|}{ Income, decile } \\
\hline 1st and 2nd & $1,168(13.1)$ & $288(13.3)$ & $111(12.8)$ & $37(9.8)$ & $78(13.1)$ & 0.406 \\
\hline 3rd and 4th & $1,127(12.6)$ & $263(12.1)$ & $113(13.0)$ & $46(12.2)$ & $53(8.9)$ & 0.039 \\
\hline 5 th and 6th & $1,288(14.4)$ & $326(15.0)$ & $97(11.2)$ & $63(16.7)$ & $66(11.1)$ & 0.044 \\
\hline 7th and 8th & $1,735(19.5)$ & $416(19.2)$ & $178(20.5)$ & $70(18.5)$ & $115(19.3)$ & 0.957 \\
\hline 9th and 10th & $2,503(28.1)$ & $625(28.8)$ & $268(30.9)$ & $117(31.0)$ & $205(34.3)$ & $<0.001$ \\
\hline Not recorded & $1,094(12.3)$ & $253(11.7)$ & $101(11.6)$ & $45(11.9)$ & $80(13.4)$ & - \\
\hline Admission to tertiary referral hospital & $2,474(27.8)$ & $702(32.3)$ & $276(31.8)$ & $116(30.7)$ & $241(40.4)$ & $<0.001$ \\
\hline \multicolumn{7}{|l|}{ Comorbidities } \\
\hline Cerebrovascular accident & $936(10.5)$ & $253(11.7)$ & $117(13.5)$ & $46(12.2)$ & $82(13.7)$ & $<0.001$ \\
\hline Moderate to severe chronic kidney disease & $790(8.9)$ & $177(8.2)$ & $83(9.6)$ & $39(10.3)$ & $87(14.6)$ & $<0.001$ \\
\hline Chronic liver disease & $3,307(37.1)$ & $940(43.3)$ & $382(44.0)$ & $184(48.7)$ & $321(53.8)$ & $<0.001$ \\
\hline COPD & $1,248(14.0)$ & $434(20.0)$ & $177(20.4)$ & $87(23.0)$ & $154(25.8)$ & $<0.001$ \\
\hline Congestive heart failure & $1,870(21.0)$ & $479(22.1)$ & $190(21.9)$ & $77(20.4)$ & $169(28.3)$ & $<0.001$ \\
\hline Connective tissue disease & $87(1.0)$ & $26(1.2)$ & $17(2.0)$ & $9(2.4)$ & $5(0.8)$ & 0.053 \\
\hline Diabetes mellitus & $4,682(52.5)$ & $1,253(57.7)$ & $533(61.4)$ & $258(68.3)$ & $401(67.2)$ & $<0.001$ \\
\hline Malignancy & $2,108(23.6)$ & $521(24.0)$ & $220(25.3)$ & $87(23.0)$ & $168(28.1)$ & 0.003 \\
\hline Myocardial infarction & $1,158(13.0)$ & $231(10.6)$ & $99(11.4)$ & $44(11.6)$ & $83(13.9)$ & 0.377 \\
\hline Peripheral vascular disorder & $1,375(15.4)$ & $298(13.7)$ & $153(17.6)$ & $65(17.2)$ & $133(22.3)$ & $<0.001$ \\
\hline \multicolumn{7}{|l|}{ Charlson comorbidity index } \\
\hline $0-1$ & $704(7.9)$ & $206(9.5)$ & $66(7.6)$ & $13(3.4)$ & $15(2.5)$ & $<0.001$ \\
\hline $2-4$ & $3,853(43.2)$ & $833(38.4)$ & $335(38.6)$ & $142(37.6)$ & $207(34.7)$ & $<0.001$ \\
\hline$>4$ & $4,358(48.9)$ & $1,132(52.1)$ & $467(53.8)$ & $223(59.0)$ & $375(62.8)$ & $<0.001$ \\
\hline \multicolumn{7}{|l|}{ Main diagnosis at the initiation of MV } \\
\hline Respiratory disorder & $1,375(15.4)$ & $526(24.2)$ & $220(25.3)$ & $94(24.9)$ & $192(32.2)$ & $<0.001$ \\
\hline Cardiovascular disorder & $3,098(34.8)$ & $555(25.6)$ & $205(23.6)$ & $83(22.0)$ & $116(19.4)$ & $<0.001$ \\
\hline No. of days spent in the hospital & $20.87 \pm 22.09$ & $29.18 \pm 24.95$ & $37.24 \pm 25.22$ & $46.25 \pm 27.40$ & $74.49 \pm 53.67$ & $<0.001$ \\
\hline No. of days spent in the ICU & $7.05 \pm 9.10$ & $14.65 \pm 10.44$ & $22.50 \pm 14.04$ & $30.95 \pm 16.28$ & $62.86 \pm 51.20$ & $<0.001$ \\
\hline No. of days using mechanical ventilator & $2.33 \pm 1.59$ & $9.43 \pm 1.97$ & $16.46 \pm 1.99$ & $23.77 \pm 1.97$ & $51.86 \pm 41.93$ & $<0.001$ \\
\hline Bedside therapeutic exercise & $3,944(99.2)$ & $1,109(99.2)$ & $498(99.0)$ & $234(98.3)$ & $398(98.3)$ & 0.023 \\
\hline Rehabilitative breathing therapy & $196(4.9)$ & $71(6.4)$ & $27(5.4)$ & $23(9.7)$ & $39(9.6)$ & $<0.001$ \\
\hline
\end{tabular}

Values are presented as mean \pm standard deviation or as number of patients (\%).

MV: mechanical ventilation; ICU: intensive care unit; COPD: chronic obstructive pulmonary disease.

\section{Rate of ICU readmission}

The rate of ICU readmission increased as MV duration increased (Table 3 ). Compared to patients with MV for $<7$ days, the unadjusted incidence rate ratio (IRR) was higher in the patients with longer MV duration (patients with MV for 7-13 days, 1.30 [95\% confidence interval (CI), 1.24-1.35]; patients with MV for 14-20 days, 1.63 [95\% CI, 1.53-1.74]; patients with 
Table 2. Clinical outcomes of ICU management according to the MV duration

\begin{tabular}{|c|c|c|c|c|c|c|}
\hline & $\begin{array}{c}\text { MV for } \\
<7 \text { days } \\
(n=8,915)\end{array}$ & $\begin{array}{l}\text { MV for } \\
7-13 \text { days } \\
(n=2,171)\end{array}$ & $\begin{array}{c}\text { MV for } \\
\text { 14-20 days } \\
(n=868)\end{array}$ & $\begin{array}{c}\text { MV for } \\
21-27 \text { days } \\
(n=378)\end{array}$ & $\begin{array}{l}\text { MV for } \\
\geq 28 \text { days } \\
(n=597)\end{array}$ & $\begin{array}{l}\mathrm{p} \text {-value } \\
\text { for trend }\end{array}$ \\
\hline \multicolumn{7}{|l|}{ Result of ICU management } \\
\hline Discharge to home & $2,619(29.4)$ & $695(32.0)$ & $238(27.4)$ & $95(25.1)$ & $161(27.0)$ & $<0.001$ \\
\hline Transfer to other hospital & $113(1.3)$ & $37(1.7)$ & $21(2.4)$ & $12(3.2)$ & $11(1.8)$ & 0.001 \\
\hline Return to previous health care unit & $102(1.1)$ & $48(2.2)$ & $11(1.3)$ & $5(1.3)$ & $15(2.5)$ & 0.004 \\
\hline In-hospital death & $4,210(47.2)$ & $885(40.8)$ & $383(44.2)$ & $177(46.8)$ & $307(51.4)$ & 0.810 \\
\hline \multicolumn{7}{|l|}{ Readmission to the ICU } \\
\hline $\begin{array}{l}\text { Readmission within } 2 \text { days after } \\
\text { discharge to ward }\end{array}$ & $12(0.1)$ & $5(0.2)$ & $1(0.1)$ & $1(0.3)$ & $1(0.2)$ & 0.840 \\
\hline $\begin{array}{l}\text { Readmission within } 3 \text { days after } \\
\text { discharge to ward }\end{array}$ & $14(0.2)$ & $7(0.3)$ & $2(0.2)$ & $1(0.3)$ & $3(0.5)$ & 0.283 \\
\hline $\begin{array}{l}\text { Readmission within } 7 \text { days after } \\
\text { discharge to ward }\end{array}$ & $33(0.4)$ & $18(0.8)$ & $5(0.6)$ & $3(0.8)$ & $4(0.7)$ & 0.060 \\
\hline $\begin{array}{l}\text { Readmission within } 28 \text { days after } \\
\text { discharge to ward }\end{array}$ & $63(0.7)$ & $42(1.9)$ & $14(1.6)$ & $13(3.4)$ & $24(4.0)$ & $<0.001$ \\
\hline Total readmission after discharge to ward & $1,236(13.9)$ & $362(16.7)$ & $168(19.4)$ & $77(20.4)$ & $213(35.7)$ & $<0.001$ \\
\hline \multicolumn{7}{|l|}{ Source of readmission to the ICU } \\
\hline $\begin{array}{l}\text { From a general ward before hospital } \\
\text { discharge }\end{array}$ & $925(10.4)$ & $253(11.7)$ & $130(15.0)$ & $58(15.3)$ & $177(29.6)$ & $<0.001$ \\
\hline After hospital discharge & $311(3.5)$ & $109(5.0)$ & $38(4.4)$ & $19(5.0)$ & $36(6.0)$ & $<0.001$ \\
\hline Total death & $5,560(62.4)$ & $1,396(64.3)$ & $615(70.9)$ & $281(74.3)$ & $457(76.5)$ & $<0.001$ \\
\hline
\end{tabular}

Values are presented as number (\%).

ICU: intensive care unit; MV: mechanical ventilation.
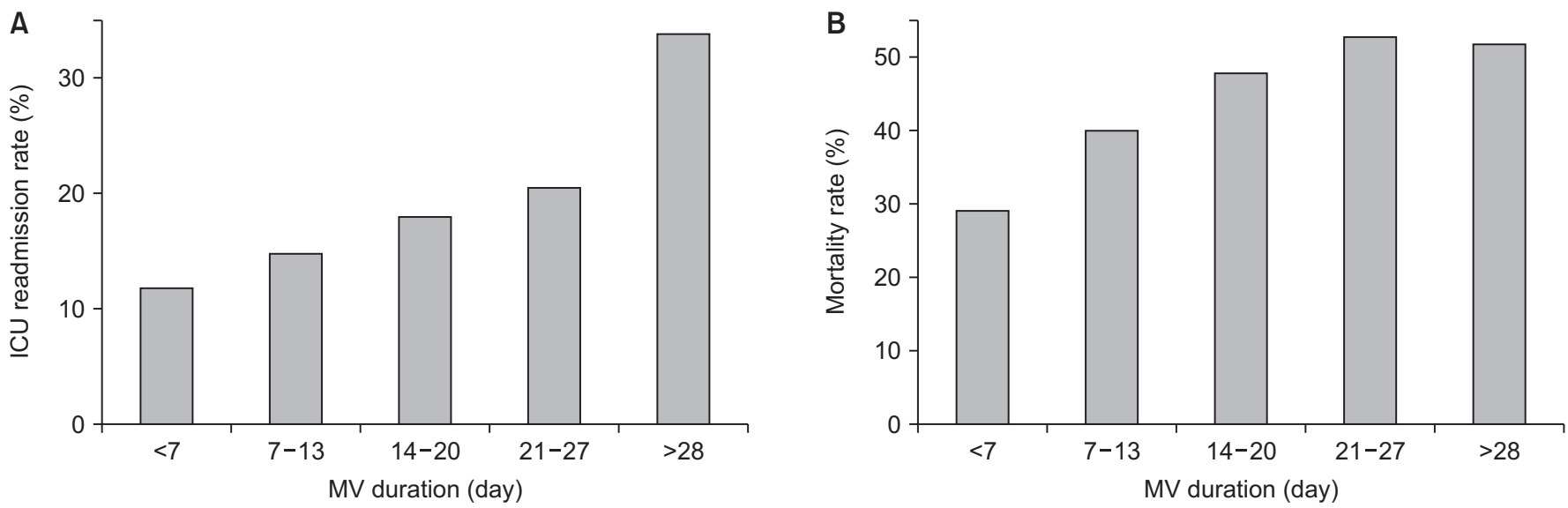

Figure 2. The intensive care unit (ICU) readmission and total death after discharge to the ward in surviving ICU patients. (A) The ICU readmission rate increases according to the mechanical ventilation (MV) duration, especially in patients with the MV for $\geq 28$ days. (B) The mortality rate after the ICU discharge increases according to the MV duration, with more than half of patients with the MV for $\geq 21$ days dying after discharge to the ward even though they survived in the ICU.

MV for 21-27 days, 1.75 [95\% CI, 1.60-1.93]; patients with MV for $\geq 28$ days, 2.82 [95\% CI, 2.62-3.03]). Although attenuated, the adjusted IRR in patients with longer MV was significantly higher in patients with longer MV duration (patients with MV for 7-13 days, 1.01 [95\% CI, 1.00-1.03]; patients with MV for 14-20 days, 1.03 [95\% CI 1.01-1.06]; patients with MV for 
Table 3. Comparison of the unadjusted and adjusted incidence rates of the ICU readmission according to the MV duration

\begin{tabular}{|c|c|c|c|c|c|}
\hline & $\begin{array}{c}\text { MV for }<7 \text { days } \\
\quad(n=8,915)\end{array}$ & $\begin{array}{c}\text { MV for } 7-13 \\
\text { days }(n=2,171)\end{array}$ & $\begin{array}{l}\text { MV for } 14-20 \\
\text { days }(n=868)\end{array}$ & $\begin{array}{l}\text { MV for } 21-27 \\
\text { days }(n=378)\end{array}$ & $\begin{array}{l}\text { MV for } \geq 28 \text { days } \\
(n=597)\end{array}$ \\
\hline \multicolumn{6}{|l|}{ ICU readmission } \\
\hline Total person-time (person-year) & 17,903 & 3,445 & 1,120 & 458 & 507 \\
\hline Incidence rate (per 1,000 person-years) & 69 & 105 & 150 & 168 & 420 \\
\hline Adjusted incidence rate ratio* $(95 \% \mathrm{CI})$ & 1.00 & $1.01(1.00-1.03)$ & $1.03(1.01-1.06)$ & $1.04(1.00-1.07)$ & $1.15(1.11-1.18)$ \\
\hline
\end{tabular}

Incidence rate ratio was estimated based on the incidence rate of the patients with $\mathrm{MV}$ for $<7$ days.

*Poisson regression analysis was conducted with variables, including age, sex, income, admission to tertiary referral hospital, Charlson comorbidity index, main diagnosis at the initiation of the MV, and the follow-up duration.

ICU: intensive care unit; MV: mechanical ventilation; CI: confidence interval.

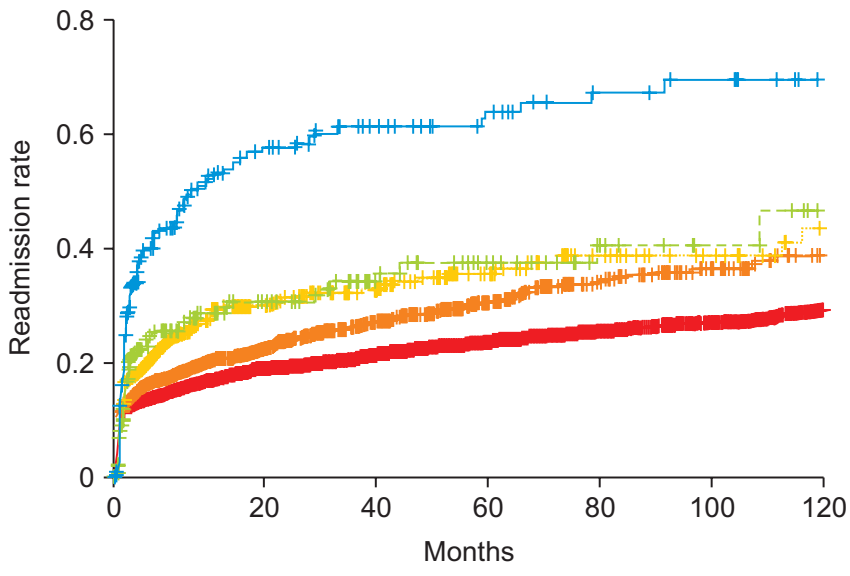

Figure 3. The Kaplan-Meier curve to evaluate the time to readmission according to mechanical ventilation duration. Red line, MV for $<7$ days; orange line, MV for 7-13 days; yellow line, MV for 14-20 days; green line, MV for 21-27 days; blue line, MV for $>27$ days. Logrank test in comparison with $<7$ days (red line) vs. $7-13$ days (orange line): $\mathrm{p}=0.003$. Log-rank test in comparison with $<7$ days (red line) vs. $7-13$ days (yellow line): $\mathrm{p}<0.001$. Log-rank test in comparison with $<7$ days (red line) vs. $7-13$ days (green line): $\mathrm{p}<0.001$. Log-rank test in comparison with $<7$ days (red line) vs. $7-13$ days (blue line): $\mathrm{p}<0.001$. Log-rank test in comparison with $7-13$ days (orange line) vs. 14-20 days (yellow line): $\mathrm{p}=0.055$. Log-rank test in comparison with $7-13$ days (orange line) vs. $21-27$ days (green line): $\mathrm{p}=0.083$. Log-rank test in comparison with 7-13 days (orange line) vs. $>27$ days (blue line): $\mathrm{p}<0.001$. Log-rank test in comparison with 14-20 days (yellow line) vs. 21-27 days (green line): p=0.811. Log-rank test in comparison with 14-20 days (yellow line) vs. $>27$ days (blue line): $\mathrm{p}<0.001$. Log-rank test in comparison with 21-27 days (green line) vs. $>27$ days (blue line): $\mathrm{p}<0.001$.

21-27 days, 1.04 [95\% CI 1.00-1.07]; patients with MV for $\geq 28$ days, 1.15 [95\% CI 1.11-1.18]).

In the Kaplan-Meier curves, the length of time to ICU readmission was significantly longer in patients with MV for $<7$ days and shorter in those with MV for $\geq 28$ days (Figure 3 ).
There was no significant difference between patients with MV for 7-13 days, 14-20 days, and 21-27 days. The results of the log-rank test are described in the footnote of Figure 3.

In the analysis weighted with multinomial propensity scores, ICU readmission was significantly associated with MV for 7-13 days (odds ratio [OR], 1.02 [95\% CI, 1.01-1.02]; $\mathrm{p}<0.001$ ), MV for 14-20 days (OR, 1.03 [95\% CI, 1.02-1.05]; $\mathrm{p}<0.001$ ), and $\mathrm{MV}$ for $>27$ days (OR, 1.19 [95\% CI, 1.13-1.26]; $\mathrm{p}<0.001$ ), but not MV for 21-27 days (OR, 1.04 [95\% CI, 0.991.09]; $\mathrm{p}=0.122$ ). In the unadjusted regression analysis with a Cox proportional hazards model, we found that age, income, admission to tertiary hospital, CCI $>4$, respiratory disorder as main diagnosis at the initiation of MV, MV duration, and rehabilitative breathing therapy were significantly related to ICU readmission (Table 4). Similar results were found in the multivariable analysis (MV duration: hazard ratio, 1.058 [95\% CI, 1.047-1.069]; $\mathrm{p}<0.001)$.

\section{Discussion}

We found that the ICU readmission rate was significantly related to MV duration. About $30 \%$ of critically ill patients with MV who survived in ICU were eventually readmitted to ICU. There was a significant linear relationship between MV duration and ICU readmission. The IRR of ICU readmission was higher in patients with longer MV and similar results were found in the survival analysis and the analyses adjusted by multinomial propensity scores. The regression analysis with a Cox proportional hazards model showed a higher risk of ICU readmission in patients with PMV. Considering that the event of MV definitely preceded the event of ICU readmission, a causal relationship can be established, and prolonged MV duration should be regarded as one of the preceding risk factors for ICU readmission.

The reason why PMV increases ICU readmission has not been well discussed before. Cohort study has been rarely 
Table 4. Results of the unadjusted and adjusted regression analysis with the Cox proportional hazards model to evaluate the risk of intensive care unit readmission

\begin{tabular}{|c|c|c|c|c|}
\hline \multirow{2}{*}{ Variable } & \multicolumn{2}{|c|}{ Univariable analysis } & \multicolumn{2}{|c|}{ Multivariable analysis } \\
\hline & HR $(95 \% \mathrm{CI})$ & p-value & HR $(95 \% \mathrm{CI})$ & p-value \\
\hline Age & $1.029(1.026-1.033)$ & $<0.001$ & $1.027(1.022-1.032)$ & $<0.001$ \\
\hline Male sex & $1.003(0.919-1.096)$ & 0.943 & - & - \\
\hline Residence & $0.932(0.854-1.017)$ & 0.115 & - & - \\
\hline Income, decile & $0.976(0.963-0.988)$ & $<0.001$ & $0.971(0.956-0.987)$ & $<0.001$ \\
\hline Admission to tertiary referral hospital & $1.781(1.63-1.947)$ & $<0.001$ & $1.355(1.159-1.583)$ & $<0.001$ \\
\hline Charlson comorbidity index $>4$ & $2.126(1.937-2.332)$ & $<0.001$ & $1.864(1.654-2.101)$ & $<0.001$ \\
\hline $\begin{array}{l}\text { Respiratory disorder as main diagnosis } \\
\text { at the initiation of MV }\end{array}$ & $1.899(1.721-2.095)$ & $<0.001$ & $1.300(1.096-1.541)$ & 0.003 \\
\hline MV duration, week & $1.076(1.067-1.085)$ & $<0.001$ & $1.058(1.047-1.069)$ & $<0.001$ \\
\hline Bedside therapeutic exercise & $1.161(0.603-2.235)$ & 0.656 & - & - \\
\hline Rehabilitative breathing therapy & $1.301(1.063-1.594)$ & 0.011 & $1.234(1.007-1.513)$ & 0.042 \\
\hline
\end{tabular}

HR: hazard ratio; CI: confidence interval; MV: mechanical ventilation.

carried out and only case-control studies showing PMV as a risk factor for ICU readmission has been reported ${ }^{9,18}$. PMV increased ICU length of stay (LOS) ${ }^{19}$ and a risk of infection, acute kidney injury, coagulopathy, respiratory failure, and shock $^{20}$. Prolonged LOS in ICU was associated with a higher 1-year mortality rate ${ }^{21}$. We made hypotheses for the mechanism of relationship between PMV and prolonged ICU LOS. First, patients with PMV often have relatively lower respiratory muscle performance that cannot compensate for increased respiratory demand ${ }^{22,23}$. Second, diaphragm atrophy has been described as one of the reasons for the poor prognosis in $\mathrm{PMV}^{24}$. Third, systemic muscle weakness is more common in ICU patients with acute respiratory distress syndrome who needed to stay in bed for longer periods with $\mathrm{MV}^{25}$. PMV increased a risk of ICU-acquired weakness or critical illness myopathy that attributes sepsis, immobility, multi-organ failure, and hyperglycemia ${ }^{26}$. Lastly, patients with long-term MV may experience a decline in cognitive function and require additional hospitalization ${ }^{27}$. Early-onset delirium is associated with $\mathrm{PMV}^{28}$. A lower rate of successful extubation and a higher rate of neurocognitive and psychological dysfunction have been found when MV duration was prolonged ${ }^{1,29-31}$. Therefore, the patients with PMV may be readmitted to the ICU because of their reduced physiologic reservoirs to fight against new respiratory problems.

The clinical severity of patient condition in ICU has a considerable influence on MV duration. In a previous study, MV duration and clinical severity on day 1 had an inverted U shape relationship ${ }^{32}$. A higher grade of initial clinical severity does not necessarily mean that the MV duration will be prolonged, because shorter MV duration due to early death is usually observed in patients with severe respiratory failure ${ }^{33}$. Rather, the clinical condition over the course of MV has been considered as a more important issue than the initial clinical severity $^{34}$. In fact, when the intensivist predicts MV duration based on the clinical information within 48 hours of MV, the accuracy of prediction is not high ${ }^{35}$. In contrast, a small observational study showed that clinical severity scores identified after 48 hours of MV better predicted which patients would have an MV duration $>7$ days $^{36}$. MV duration is a factor that reflects the overall clinical course rather than the clinical severity at a particular time, which would be one of the explanations why ICU readmission can be predicted by MV duration.

The first strength of the present study is its well-verified cohort with a large sample population and 10-year followup duration ${ }^{15}$. Because of cohort design, causality can be clarified. The second strength is the reliability of the sociodemographic data, which is difficult to obtain from individual research institutes ${ }^{7}$. We used the credible socio-demographic information which was collected by the Korean Health and Welfare Department. The thirst strength is that, even though patients were admitted to different hospitals, we were able to accurately verify ICU readmission, duration of MV, ICU stay, and hospitalization for all patients in the cohort.

There were some limitations to this study. First, clinical condition and severity were not addressed in our study. As mentioned before, it is important to understand the clinical severity at the time of discharge from ICU, which cannot be ascertained from claim data. Second, our study cohort could not provide the reasons for MV implementation or ICU readmission. Although limited, we used the main diagnosis at the time of MV to determine the reason for MV. Third, we could not elucidate any specific treatments that can affect the MV duration. The specific methods for intensive care were not distinguishable in this claim data.

In conclusion, the patients who are discharged from the ICU 
following long periods of MV need closer monitoring. This finding is important when formulating an accurate model to predict ICU readmission and planning surveillance of patients discharged from the ICU. Our findings also provide a perspective for future studies investigating the impact of alternative interventions to conventional MV.

\section{Authors' Contributions}

Conceptualization: Lee HW. Formal analysis: Lee HW, Cho YJ. Investigation: Lee HW. Writing - original draft preparation: Lee HW. Writing - review and editing: Cho YJ. Approval of final manuscript: all authors.

\section{Conflicts of Interest}

No potential conflict of interest relevant to this article was reported.

\section{Funding}

This work was supported by the grant from Korea Health Technology R \& D Project through the Korea Health Industry Development Institute (KHIDI), funded by the Ministry of Health \& Welfare, Republic of Korea (grant number: HI16C1787).

\section{Supplementary Material}

Supplementary material can be found in the journal homepage (http://www.e-trd.org).

Supplementary Table S1. Admission and treatment codes used to identify the patients who met the operational definition used in this study.

\section{References}

1. Metnitz PG, Fieux F, Jordan B, Lang T, Moreno R, Le Gall JR. Critically ill patients readmitted to intensive care units: lessons to learn? Intensive Care Med 2003;29:241-8.

2. Renton J, Pilcher DV, Santamaria JD, Stow P, Bailey M, Hart G, et al. Factors associated with increased risk of readmission to intensive care in Australia. Intensive Care Med 2011;37:18008.

3. Rosenberg AL, Hofer TP, Hayward RA, Strachan C, Watts CM. Who bounces back? Physiologic and other predictors of intensive care unit readmission. Crit Care Med 2001;29:511-8.

4. Rosenberg AL, Watts C. Patients readmitted to ICUs: a sys- tematic review of risk factors and outcomes. Chest 2000;118: 492-502.

5. Gajic O, Malinchoc M, Comfere TB, Harris MR, Achouiti A, Yilmaz M, et al. The Stability and Workload Index for Transfer score predicts unplanned intensive care unit patient readmission: initial development and validation. Crit Care Med 2008;36:676-82.

6. Ouanes I, Schwebel C, Francais A, Bruel C, Philippart F, Vesin A, et al. A model to predict short-term death or readmission after intensive care unit discharge. J Crit Care 2012;27:422.

7. Ponzoni CR, Correa TD, Filho RR, Serpa Neto A, Assuncao MS, Pardini A, et al. Readmission to the intensive care unit: incidence, risk factors, resource use, and outcomes: a retrospective cohort study. Ann Am Thorac Soc 2017;14:1312-9.

8. Campbell AJ, Cook JA, Adey G, Cuthbertson BH. Predicting death and readmission after intensive care discharge. Br J Anaesth 2008;100:656-62.

9. Hill AD, Fowler RA, Burns KE, Rose L, Pinto RL, Scales DC. Long-term outcomes and health care utilization after prolonged mechanical ventilation. Ann Am Thorac Soc 2017;14: 355-62.

10. Damuth E, Mitchell JA, Bartock JL, Roberts BW, Trzeciak S. Long-term survival of critically ill patients treated with prolonged mechanical ventilation: a systematic review and metaanalysis. Lancet Respir Med 2015;3:544-53.

11. Oeyen SG, Vandijck DM, Benoit DD, Annemans L, Decruyenaere JM. Quality of life after intensive care: a systematic review of the literature. Crit Care Med 2010;38:2386-400.

12. Kress JP, Pohlman AS, O'Connor MF, Hall JB. Daily interruption of sedative infusions in critically ill patients undergoing mechanical ventilation. N Engl J Med 2000;342:1471-7.

13. Brook AD, Ahrens TS, Schaiff R, Prentice D, Sherman G, Shannon W, et al. Effect of a nursing-implemented sedation protocol on the duration of mechanical ventilation. Crit Care Med 1999;27:2609-15.

14. von Elm E, Altman DG, Egger M, Pocock SJ, Gotzsche PC, Vandenbroucke JP, et al. The Strengthening the Reporting of Observational Studies in Epidemiology (STROBE) statement: guidelines for reporting observational studies. Lancet 2007; 370:1453-7.

15. Lee J, Lee JS, Park SH, Shin SA, Kim K. Cohort Profile: The National Health Insurance Service-National Sample Cohort (NHIS-NSC), South Korea. Int J Epidemiol 2017;46:e15.

16. Lee HW, Ji E, Ahn S, Yang HJ, Yoon SY, Park TY, et al. A population-based observational study of patients with pulmonary disorders in intensive care unit. Korean J Intern Med 2019 Nov 25 [Epub]. https://doi.org/10.3904/kjlm.2018.449.

17. Burgette L, Griffin BA, McCaffrey D; RAND Corporation. Propensity scores for multiple treatments: a tutorial for the mnps function in the twang package. Santa Monica: RAND Corporation; 2017.

18. Brown SE, Ratcliffe SJ, Kahn JM, Halpern SD. The epidemiology of intensive care unit readmissions in the United States. 
Am J Respir Crit Care Med 2012;185:955-64.

19. Lone NI, Walsh TS. Prolonged mechanical ventilation in critically ill patients: epidemiology, outcomes and modelling the potential cost consequences of establishing a regional weaning unit. Crit Care 2011;15:R102.

20. Arabi Y, Venkatesh S, Haddad S, Al Shimemeri A, Al Malik S. A prospective study of prolonged stay in the intensive care unit: predictors and impact on resource utilization. Int J Qual Health Care 2002;14:403-10.

21. Moitra VK, Guerra C, Linde-Zwirble WT, Wunsch H. Relationship between ICU length of stay and long-term mortality for elderly ICU survivors. Crit Care Med 2016;44:655-62.

22. Jubran A, Tobin MJ. Pathophysiologic basis of acute respiratory distress in patients who fail a trial of weaning from mechanical ventilation. Am J Respir Crit Care Med 1997;155:90615.

23. Appendini L, Purro A, Patessio A, Zanaboni S, Carone M, Spada E, et al. Partitioning of inspiratory muscle workload and pressure assistance in ventilator-dependent COPD patients. Am J Respir Crit Care Med 1996;154:1301-9.

24. Goligher EC, Dres M, Fan E, Rubenfeld GD, Scales DC, Herridge MS, et al. Mechanical ventilation-induced diaphragm atrophy strongly impacts clinical outcomes. Am J Respir Crit Care Med 2018;197:204-13.

25. Schweickert WD, Hall J. ICU-acquired weakness. Chest 2007;131:1541-9.

26. Griffiths RD, Hall JB. Intensive care unit-acquired weakness. Crit Care Med 2010;38:779-87.

27. Turon M, Fernandez-Gonzalo S, de Haro C, Magrans R, Lopez-Aguilar J, Blanch L. Mechanisms involved in brain dysfunction in mechanically ventilated critically ill patients: implications and therapeutics. Ann Transl Med 2018;6:30.

28. Lin SM, Huang CD, Liu CY, Lin HC, Wang CH, Huang PY, et al.
Risk factors for the development of early-onset delirium and the subsequent clinical outcome in mechanically ventilated patients. J Crit Care 2008;23:372-9.

29. Scheinhorn DJ, Hassenpflug MS, Votto JJ, Chao DC, Epstein SK, Doig GS, et al. Post-ICU mechanical ventilation at 23 longterm care hospitals: a multicenter outcomes study. Chest 2007;131:85-93.

30. O'Connor HH, Kirby KJ, Terrin N, Hill NS, White AC. Decannulation following tracheostomy for prolonged mechanical ventilation. J Intensive Care Med 2009;24:187-94.

31. Jubran A, Lawm G, Kelly J, Duffner LA, Gungor G, Collins EG, et al. Depressive disorders during weaning from prolonged mechanical ventilation. Intensive Care Med 2010;36:828-35.

32. Seneff MG, Zimmerman JE, Knaus WA, Wagner DP, Draper EA. Predicting the duration of mechanical ventilation. The importance of disease and patient characteristics. Chest 1996;110:469-79.

33. Gadre SK, Duggal A, Mireles-Cabodevila E, Krishnan S, Wang $\mathrm{XF}$, Zell K, et al. Acute respiratory failure requiring mechanical ventilation in severe chronic obstructive pulmonary disease (COPD). Medicine (Baltimore) 2018;97:e0487.

34. Esteban A, Anzueto A, Frutos F, Alia I, Brochard L, Stewart TE, et al. Characteristics and outcomes in adult patients receiving mechanical ventilation: a 28-day international study. JAMA 2002;287:345-55.

35. Figueroa-Casas JB, Connery SM, Montoya R, Dwivedi AK, Lee S. Accuracy of early prediction of duration of mechanical ventilation by intensivists. Ann Am Thorac Soc 2014;11:1825.

36. Hira HS, Mittal A. Evaluation of the predictors for duration of mechanical ventilation in respiratory intensive care unit. Lung India 2006;23:70-4. 